\title{
«Hay que formar unidades de autodefensa como respuesta efectiva a los hooligans antisemitas»: autodefensa judía en Uruguay, 1960-1987 ${ }^{1}$
}

\author{
"Self-Defense Units Should Be Formed as an Effective Response \\ to Anti-Semitic Hooligans": Jewish Self-Defense in Uruguay, \\ 1960-1987
}

\section{Raanan Rein}

Universidad de Tel Aviv (Israel)

https://orcid.org/0000-0002-0249-6084

\section{DOI: https://doi.org/10.25032/crh.v6i11.12 \\ Recibido: $28 / 8 / 2020$ \\ Aceptado: $2 / 10 / 2020$}

Resumen. La captura del criminal de guerra nazi Adolf Eichmann en Buenos Aires en mayo de 1960 por parte de agentes del Mossad israelí desencadenó una ola de antisemitismo violento en Argentina y Uruguay, que a su vez provocó la consolidación de un marco de autodefensa judía que se conoció en Argentina con el vocablo hebreo Irgún (organización) y en Uruguay como Bitajón (seguridad), Misgueret (marco), o simplemente en vernáculo, La Orga. Numerosos jóvenes decidieron contrarrestar el fenómeno con métodos igualmente agresivos, defendiendo a las instituciones comunitarias y castigando a los hooligans antisemitas, mostrándoles que los judíos no serían ya víctimas pasivas. Este artículo analiza tres momentos en el desarrollo de la autodefensa judía en Uruguay: el secuestro de Eichmann y sus repercusiones; la ejecución del criminal de guerra letón Herberts Cukurs en Uruguay en 1965 por parte de agentes del Mossad, y el añadido de blancos árabes a sus operaciones, especialmente en los años posteriores a la guerra de 1967 en Medio Oriente. La historiografía existente hasta ahora se ha mantenido apartada del tema y por lo tanto, este artículo intenta llenar el vacío en cuanto a la historia de la autodefensa judía, enfatizando las características peculiares de la organización en Uruguay y resaltando la influencia del

\footnotetext{
${ }_{1}$ Muchas personas me ayudaron a conseguir material relevante para esta investigación. Quiero agradecer a Idán Ring, Adrián Krupnik, Lelya Stadler, Magdalena Broquetas, David Telias, Gabriel Hojman, Jana Beris, Fernando Butazzoni y Clara Aldrighi, así como a Eliezer Nowodworski por su traducción al castellano de este artículo.
} 
sionismo revisionista de Betar y el papel de Israel y su involucramiento con estos grupos cuasi o paramilitares.

Palabras clave: Antisemitismo; Autodefensa judía; Uruguay; Israel; Herbert Cukurs; Adolf Eichmann; Mossad

Abstract. The kidnapping of Nazi war criminal Adolf Eichmann in Buenos Aires in May 1960 by Israeli Mossad agents ignited a wave of violent anti-Semitism in Argentina and Uruguay which, in turn, prompted the consolidation of Jewish self-defense organizations, known in Argentina as "the Irgun" (the Hebrew word for "organization") and in Uruguay as "Bitachon" or "Misgeret" (the Hebrew words for "security" and "framework", respectively)-or simply as "La Orga". Many Jewish-Uruguayan youngsters decided that they would defend community institutions and punish the anti-Semitic hooligans, thus showing that Jews would not be passive victims anymore. This article analyzes three key moments in the development and activities of Jewish self-defense in Uruguay: Eichmann's abduction and its repercussions; the impact of the elimination of the Latvian war criminal Herberts Cukurs in Uruguay in 1965 by Mossad agents; and the addition of Arab targets to their operations, especially in the years following the 1967 Six Day War. Current historiography has avoided the subject, and therefore this article attempts to fill the vacuum as far as the history of Jewish selfdefense is concerned, highlighting the unique characteristics of the organization in Montevideo, as well as the influence of revisionist Zionism on self-defense activities and Israel's role and involvement in these quasi-military groups.

Keywords: Anti-Semitism; Jewish self-defense; Uruguay; Israel; Herbert Cukurs; Adolf Eichmann; Mossad

\section{Introducción}

La captura del criminal de Guerra nazi Adolf Eichmann en Buenos Aires en mayo de 1960 por parte de agentes del Mossad israelí desencadenó una ola de antisemitismo violento en la Argentina, que a su vez provocó la consolidación de un marco de autodefensa judía que se conoció en su momento con el vocablo hebreo Irgún (organización) (Rein, 2015). Como ocurre a menudo, todos estos acontecimientos 
tuvieron amplias repercusiones en el país vecino, Uruguay. Los uruguayos-judíos también enfrentaron una serie de ataques y el dilema acerca de cómo reaccionar ante estas agresiones violentas. Numerosos jóvenes decidieron, al igual que sus pares argentinos-judíos, contrarrestar el fenómeno con métodos igualmente agresivos. Defenderían a las instituciones comunitarias y peticionarían ante las autoridades nacionales y municipales que se castigue encarcelando a los hooligans antisemitas, pero también «les darían una lección a esos matones, mostrándoles que los judíos no serían ya víctimas pasivas», como dijo uno de mis entrevistados. Así dieron inicio a su propia organización de autodefensa, para la que usaron nombres hebreos como Bitajón (seguridad) o Misgueret (marco), o simplemente en vernáculo, La Orga. ${ }^{2}$

Debido al pequeño tamaño de la población (estimada en alrededor de 2,5 millones en los años sesemta del siglo pasado) y de su comunidad judía (calculada en menos de cuarenta mil personas en la misma época),3 la autodefensa local no involucró a tantos jóvenes como en el caso argentino, pero estuvo bien organizada y probablemente con vínculos más estrechos con la embajada de Israel en Montevideo. Si en la Argentina Mauricio Tata Furmanski fue considerado la figura clave en la organización de la autodefensa judía local, en el caso oriental correspondió a miembros de la familia Ring, particularmente a Julio Ring, cumplir con un papel central en las actividades durante la década de 1960 y comienzos de la de 1970.

Mediante un breve análisis de tres momentos clave en el desarrollo y de las actividades de la autodefensa judía en Uruguay, el presente artículo echa un vistazo a la organización de estos grupos semi-clandestinos inmediatamente tras el secuestro de Eichmann en un suburbio del Gran Buenos Aires a comienzos de la década de 1960; el impacto de la ejecución del criminal de guerra letón Herberts Cukurs en Uruguay en 1965 por parte de agentes del Mossad en las actividades de estos grupos y el añadido de blancos árabes a sus operaciones, especialmente en los años posteriores a la guerra

\footnotetext{
${ }^{2}$ La primera Misgueret fue creada por el Mossad en Marruecos en 1956, cuando el Reino Alauita obtuvo su independencia y el estado de Israel comenzó un proyecto ilegal de inmigración de judíos-marroquíes. Véase Ian Black y Benny Morris, Israel's Secret Wars: A History of Israel's Intelligence Services. (Nueva York: Grove Press, 1991) 176.

3 U. O. Schmelz y Sergio DellaPergola, «The Demography of Latin American Jewry», American Jewish Yearbook 85 (1985): 51-102, 62; Rafael Porzecanski, El Uruguay judio: demografía e identidad. (Montevideo: Ediciones Trilce, 2006); Maya Shorer-Kaplan, «Ethnic Migration in Comparative Perspective: A Case Study of Jewish Migration from Uruguay to Israel and Other Countries, 1948-2010», Hagira - Israel Journal of Migration 6 (2016): 25-56.
} 
de 1967 en Medio Oriente.

La historiografía existente hasta ahora se ha mantenido apartada del tema, probablemente por temor a un daño a las relaciones entre el Estado de Israel y los países de América Latina o a la imagen y el status de los judíos en esos países. 4 Por esa razón, en los archivos israelíes no hay acceso a documentos relevantes. La búsqueda de diversas combinaciones para «autodefensa judía» en el catálogo del Archivo Central Sionista en Jerusalén, por ejemplo, remite a artículos que tratan sobre Rusia y Europa oriental a comienzos del siglo XX, sin mención alguna de la región latinoamericana. Por consiguiente, fue necesario realizar un Proyecto de historia oral para poder llevar a cabo esta investigación.

Este artículo tiene como objetivo llenar el vacío en cuanto a la historia de la autodefensa judía, enfatizando las características peculiares de la organización en Uruguay y resaltando a) que a pesar de que la organización era sumamente heterogénea desde el punto de vista político, ideológico y quizás también en lo social, en forma similar a lo que ocurrió al otro lado del Río de la Plata, la diferencia estriba en que en el caso oriental la influencia del sionismo revisionista de Betar fue más pronunciada, y b) que el papel de Israel y su involucramiento con estos grupos cuasi o paramilitares en Montevideo fue mucho más prominente que el que le cupo en otros países del continente.

\section{Una atmósfera de pánico conduce al establecimiento de grupos de autodefensa}

El 13 de junio de 1960 se colocaron tres bombas de fabricación casera en otras tantas sinagogas en Montevideo, dos de las cuales fueron neutralizadas antes de detonar. 5 Tras ello, dos ciudadanos uruguayos fueron arrestados como resultado de un artefacto que estalló en una casa en la que estaban manipulando materiales explosivos. Un tercer menor, César Giorgetti, ciudadano argentino de 17 años y vinculado a la Alianza Nacionalista Argentina, resultó muerto por la explosión. Uno de los jóvenes

\footnotetext{
4 En la literatura más popular sobre el tema se destacan unas pocas páginas en Fernando Amado, Mandato de Sangre (Montevideo: Sudamericana, 2012) y el libro de reciente aparición de un ex activista de la autodefensa judía en Venezuela: Isaac Cherem, Judíos sin kipa, n/p (2019).

5 «Atentados antisemitas», La Mañana [Montevideo], jun. 14, 1960; «Murió un joven terrorista y dos están gravemente heridos», El Plata [Montevideo], jun. 14, 1960; «Terrorismo en la ciudad», Acción [Montevideo], jun. 14, 1960.
} 
arrestados tenía una cruz gamada tatuada en una de sus manos (Broquetas, 2010). ${ }^{6} \mathrm{El}$ grupo contaba con conexiones transnacionales, sobre todo en Argentina, y tenía planificada una serie de ataques contra objetivos judíos, incluyendo uno contra la embajada de Israel en Montevideo. La prensa local informó que uno de los líderes en la Argentina era un alemán cuyo alias era «Willie». Diversas organizaciones de la extrema derecha en la Argentina, especialmente el Movimiento Nacionalista Tacuara, encabezado por Alberto Ezcurra Uriburu, y la Guardia Restauradora Nacionalista, mantenían vínculos estrechos con nacionalistas uruguayos (Bohoslavsky y Broquetas, 2019; Padrón, 2017).

Poco después, en el mismo mes de junio, una segunda explosión accidental causó la muerte de la persona que preparaba los artefactos. También hubo varios casos de esvásticas pintadas en las paredes de instituciones o de tiendas pertenecientes a judíos.7 Una publicación de la pequeña Liga Oriental Antisemita (LOA), de la extrema derecha, había comenzado a circular en mayo de 1960. Este fue una de varias agrupaciones extremistas en el heterogéneo mosaico de la derecha uruguaya. A pesar del reducido número de estas agrupaciones eran muy activas y tenían un mayor impacto en la sociedad uruguaya de lo que se tiende a asignar. Como resultado de estos incidentes, en gran medida un coletazo de lo ocurrido en Argentina, la policía montevideana resolvió estrechar las medidas de seguridad alrededor de las instituciones comunitarias judías. ${ }^{8}$

El embajador de Israel en Uruguay, Yitzhak Harkavi, había llegado a Sudamérica en el avión de $\mathrm{El} \mathrm{Al}$ que después llevó a Eichmann a Israel. Su testimonio, aunque adolece de varias imprecisiones, es sumamente ilustrativo:

\begin{abstract}
Llegué [a Montevideo] en mayo de 1960 con mi familia; fue apenas después de la captura de Eichmann en Argentina. La noche anterior a la presentación de credenciales nos acostamos tranquilamente a dormir... Pero a eso de las 12 de la noche recibo un llamado de Oscar Sapolinsky, que era uno de mis agregados, y me dice: «Harkavi, estalló una bomba en la comunidad sefardita; creo que no hay víctimas, pero hay un deterioro físico del edificio...» Una hora más tarde llama nuevamente Sapolinsky, que ya estuvo en el centro, y me dice que hubo bombas que no estallaron, en la comunidad judíahúngara y en la comunidad judía de habla alemana. A las dos de la mañana, otro llamado de Sapolinsky que me dice ... que en un galpón donde se manipulaba con
\end{abstract}

\footnotetext{
${ }^{6} \mathrm{Al}$ cabo de un año y medio del acontecimiento, el propietario de la casa donde ocurrió la explosión en junio de 1960 manifestó su arrepentimiento por haber participado en actividades antisemitas. Ver «Un antisemita arrepentido» [en hebreo], Davar [Tel Aviv], ene.12, 1961: 5.

7 «Otro atentado de los nazis», El Popular [Montevideo], jun. 20, 1960.

8 «Salvaguardando instituciones judías en Uruguay» [en hebreo], Ma'ariv [Tel Aviv], jun. 17, 1960: 1.
} 
bombas había habido un estallido que mató al muchacho que manipulaba las bombas. Así, durante toda la noche. 9

Según Graciela y Victor Ben Dror (Blit) (1986), en su historia del sionismo socialista en Uruguay, ya en 1961 algunos jóvenes sionistas fueron capacitados en autodefensa e incluso compraron armas y practicaron su uso, a raíz de la ola de violencia antisemita que barrió la Argentina y Uruguay como resultante de la captura de Eichmann. ${ }^{10}$ Un testimonio similar proviene del sionismo de derechas. Julio Ring, del movimiento revisionista Betar escribió a mediados de la década de 1970, en el currículum que adjuntó para su ingreso al Mossad en Israel:

\begin{abstract}
A fines de 1961, junto con otros miembros del movimiento [Betar] fui reclutado al comando de la misgueret [la organización de autodefensa] local, debido a la intensificación del antisemitismo y del racismo. Con devoción, borré esvásticas y pintadas antisemitas [de las paredes de instituciones judías] y custodié sinagogas y asambleas públicas [judías]. La mayor parte de las veces, en el centro de la ciudad. En 1962 [mientras cursaba el primer año en la facultad de Medicina] pasé al brazo de Inteligencia de la misgueret y me ocupé en la vigilancia y recolección de información sobre blancos [sospechosos] en aquellos momentos. ${ }^{11}$
\end{abstract}

En junio de 1962, tras la ejecución de Eichmann en Israel, hubo otra serie de incidentes antisemitas en la Argentina y en Uruguay. Un pequeño grupo de uruguayos se concentró en Plaza Cagancha, en el centro de Montevideo, para celebrar una ceremonia de homenaje al ex oficial de la Gestapo, dejando una corona de flores con una nota que decía «Las Juventudes Nacionalistas Orientales en memoria de A. Eichmann, soldado de la causa de los pueblos asesinados por el judaísmo internacional». ${ }^{12}$ Unos días más tarde, cuatro jóvenes quemaron una bandera israelí y dejaron un panfleto que decía «In memoriam de Adolf Eichmann ASESINADO por la judería internacional. Las juventudes uruguayas le rinden homenaje». Nadie fue arrestado. ${ }^{13}$ Poco después fue lanzada una bomba contra una sede del Partido Comunista. La prensa local señaló a la LOA y al Frente Estudiantil de Acción Nacional

\footnotetext{
9 Itzjak Harkavi, «En Uruguay durante la época de la captura de Eichmann». Historia viva: memorias del Uruguay y de Israel, (Jerusalén: Universidad Hebrea, 1989), 130-131; Entrevista del autor con Aida Stoler vía Zoom, abril de 2020.

${ }^{10}$ Aún así, Aharon Melika, emisario del movimiento Ha-Shomer Hatzair en Montevideo en 1965-1969, no recuerda una participación activa de la juventud sionista socialista en actividades de autodefensa. Correspondencia del autor con Graciela Ben Dror por correo electrónico, abril de 2020.

${ }^{11}$ Curriculum Vitae manuscrito de Julio Ring, entregado al Mossad en 1974.

12 «A Eichmann. Hicieron un insólito intento de homenaje», La Mañana [Montevideo], mar. 3, 1960.

13 «Fascistas en Uruguay enlutecidos por Eichmann» [en hebreo], Kol Ha'am [Tel Aviv], jun. 12, 1962: 1; «Discriminación racial», El Debate [Montevideo], jun. 11, 1962.
} 
(FEDAN) como responsables de estos ataques, destacando que sus vínculos con Tacuara eran un testimonio de «la ejecución de un plan de atentados conjuntos en ambas márgenes del Plata».14

La embajada israelí recibió numerosas amenazas telefónicas, que decían cosas como «Soy el hijo de Eichmann, señora de Harkavi. Si su marido sale a la calle mañana, lo vamos a matar. Cuídense. No salgan» (Harkavi, 132). Soledad Barrett, una activista de izquierda exiliada de su Paraguay natal, de 17 años de edad, fue secuestrada por un grupo de matones que intentó en vano obligarla a gritar vivas a Hitler en el auto. Le tatuaron una esvástica en cada muslo y la arrojaron desde el vehículo. ${ }^{15}$ Este fue un acto brutal similar al que había ocurrido hacía menos de tres semanas en Buenos Aires, con la estudiante argentina-judía Graciela Sirota. ${ }^{16}$

Pero el incidente que fue el impulso final necesario para establecer una organización de autodefensa judía en Uruguay fue la golpiza hasta la muerte en julio de 1962 de Samuel Zalzberg, un sobreviviente del Holocausto, en su oficina en Montevideo. ${ }^{17} \mathrm{Si}$ bien algunos atribuyeron a los perpetradores la intención de cometer un robo, el caso fue el disparador de fuertes reacciones por parte de la opinión pública en general y de judíos uruguayos en particular.

Como en la vecina Argentina, estas reacciones incluyeron un número creciente de judíos que emigraron a Israel, el establecimiento de una escuela integral judía y la creación de una organización de autodefensa. Padres judíos aunaron esfuerzos para establecer una escuela privada con acreditación nacional, donde los alumnos no sufrirían ataques antisemitas. El resultado fue la Escuela Integral Hebreo Uruguaya, fundada en febrero de 1962. Allí los niños recibirían tanto las asignaturas curriculares

\footnotetext{
14 «Así empezó el fascismo», Acción [Montevideo], oct. 6, 1962. Centinela, órgano de la FEDAN, publicó en su primer número un artículo negando el Holocausto judío: «Juicio o parodia», mar. 11, 1961.

15 «Los muslos de una joven uruguaya fueron tatuados con una cruz gamada» [en hebreo], Hatzofé [Tel Aviv], oct. 7, 1962: 4; «Uruguay Takes Steps to Track Down Anti-Jewish Terrorists», Jewish Telegraphic Agency [Nueva York], jul. 25, 1962. Según un informe, entre los ocho varones y muchachas que fueron secuestrados y marcados con esvásticas en aquellas semanas se encontraba un médico judío, el doctor Máximo Handel, mientras que la mayor parte de los otros estaban empleados por judíos, sea en tiendas o en servicio doméstico. Ver Jewish Telegraphic Agency [Nueva York], jul. 30, 1962: 1.

${ }^{16}$ Raanan Rein, Argentina, Israel y los judíos: encuentros y desencuentros, mitos y realidades. (Buenos Aires: Lumiere, 2001), cap. 7.

${ }_{17}$ Jewish Telegraphic Agency [Nueva York], jul. 30, 1962: 1. Véase también «Anti-Semitic Violence Flares in South America», Rhode Island Herald [Rhode Island], ago. 10, 1962; New Jersey Jewish News [New Jersey], ago. 3, 1962.
} 
nacionales como educación en cuestiones de religión y cultura judía. Uno de los padres fundadores era el respetado dentista Mario Kronenberg, que fue también uno de los fundadores de la organización de autodefensa judía. ${ }^{18}$ En este último proyecto participaron también Julio Mario Blankleder, Mario Julio Yudka Ring (primo del ya mencionado Julio Ring) y Jorge Hacas «el único proveniente de la izquierda sionista». ${ }^{19}$

A diferencia de lo que ocurrió en Argentina, la formación de grupos de autodefensa en Uruguay no fue un secreto y la prensa israelí cubrió el caso con bastante amplitud, tanto en diarios de la izquierda identificados con el Laborismo gobernante como en los de la derecha, alineados con el Revisionismo opositor. Davar, el órgano de la Confederación General de los Trabajadores (Histadrut) enunció en primera plana que patrullas armadas de grupos de autodefensa fueron vistos en Montevideo custodiando hogares de judíos y sinagogas. El matutino citaba a un portavoz de la comunidad que se refirió a esta iniciativa de protección de vidas humanas y de patrimonio de judíos. ${ }^{20}$ Herut, del partido revisionista de derecha del mismo nombre, también publicó en un lugar destacado sobre la creación de unidades de autodefensa judía en la capital uruguaya. ${ }^{21}$

En noviembre de 1962 se celebrarían elecciones nacionales y la polarización política propició el surgimiento de grupos más extremos. Desde 1958 el país estaba gobernado por el Partido Nacional, conservador y más nacionalista, después de casi un siglo de gobiernos colorados, un partido más liberal y reformista. Pero el sistema bipartidario tradicional (a pesar de que ambos partidos incluían distintos sectores) parecía incapaz de afrontar las dificultades económicas, las crecientes demandas sociales y la polarización política. En 1962 y más aun en 1966, las pequeñas agrupaciones de izquierda mejorarían sus resultados en las urnas, aunque el porcentaje de todas estas agrupaciones en conjunto fue menor al $10 \%$.

A pesar de no haber tenido la misma magnitud que en Argentina, estos

\footnotetext{
${ }^{18}$ Entrevista telefónica del autor con su hijo, Gustavo Kronenberg, abril de 2020.

19 Entrevista del autor con C. G., abril de 2020.

${ }_{20}$ «Autodefensa establecida por judíos de Montevideo tras asesinato de un anciano judío», [en hebreo] Davar [Tel Aviv], jul. 26, 1962: 1.

${ }^{21}$ «Judíos de Montevideo establecen unidades de autodefensa tras el asesinato de Samuel Zalzberg», [en hebreo] Herut [Tel Aviv], jul. 26, 1962: 1.
} 
incidentes antisemitas crearon una atmósfera de pánico entre los judíos locales. Un judío-uruguayo disparó contra un taxista en julio de 1962, cuando este había aminorado su marcha en una calle relativamente desierta, lo que despertó el temor de que pudiera tratarse de un intento de secuestro o un ataque, como había ocurrido con otros judíos en los días anteriores. ${ }^{22}$ Pinchas Said, a la sazón de 22 años de edad, una figura prominente en las actividades de autodefensa, murió en circunstancias similares. Aparentemente, se vio involucrado en una discusión con el conductor de un ómnibus y resultó acuchillado. Sus padres trasladaron a bordo del Flaminia sus restos a Israel, para ser enterrados en dicho país, en marzo de $1963 .{ }^{23}$

Los judíos uruguayos estaban menos acostumbrados al racismo violento y a la xenofobia que sus pares argentinos. A comienzos de la década de 1960, los judíos eran parte integral de la sociedad uruguaya. Este nuevo tipo de ataques debe ser considerado en el contexto de circunstancias nacionales caracterizado por una creciente violencia política y tensiones sociales debidas a huelgas sindicales y la represión policial, que ampliando la mira se insertan en el trasfondo de la Guerra Fría y las secuelas de la revolución cubana en los países del continente (Broquetas, 2012). La polarización en aumento de la política uruguaya, así como la mayor efervescencia social tienen también explicaciones en el descenso de la actividad económica. La prosperidad que había caracterizado la primera década del período posterior a la Segunda Guerra Mundial mermó (Alonso y Demasi, 1986; Nahum, 2007). Todos los indicadores económicos apuntaban al estancamiento del país y al deterioro del nivel de vida de las clases trabajadoras y de las clases medias. En este panorama, la acción de las bandas armadas anticomunistas era una característica destacada y la supuesta ineficacia de la policía para investigar y reprimir a los atacantes despertaba sospechas. En Uruguay, como en otros lugares, las actividades de autodefensa tuvieron su origen en la falta de confianza en las fuerzas de seguridad nacional para proteger a los judíos de los elementos antisemitas.

La década de 1960 fue también una era de creciente participación en la política por parte de jóvenes activistas latinoamericanos, tanto en la izquierda como en la

\footnotetext{
22 «Pánico entre judíos uruguayos tras el asesinato de un anciano: se está organizando una autodefensa - Los estudiantes pararán mañana», [en hebreo] Hatzofé [Tel Aviv], jul. 27, 1962: 1.

23 «Los padres de Sudamérica cumplieron la voluntad de su hijo», [en hebreo] Ma'ariv [Tel Aviv], abr. 1, 1963: 16; «Los restos de un joven asesinado en un ataque antisemita fueron traídos en un barco de olim», [en hebreo] Hatzofé [Tel Aviv], abr. 1, 1963: 4.
} 
derecha, judíos y no judíos, que buscaban diferenciarse de las generaciones de sus mayores y estaban dispuestos a asumir riesgos y embarcarse en actividades «heroicas». Tanto las agresiones antisemitas como la organización de autodefensa judía reflejan esta atmósfera. El uso de la violencia contaba cada vez con más legitimidad entre los jóvenes revolucionarios de todas las tendencias e inclinaciones.

El estudiantado universitario del Uruguay estaba muy politizado y no pocos participaban en actividades nacionalistas (Broquetas 2010 y 2012). El papel de los estudiantes en la campaña antisemita había quedado claro ya para observadores contemporáneos. En su informe para el anuario del Comité Judío de Estados Unidos, American Jewish Yearbook, Nelson Pilosof se refirió a las «organizaciones estudiantiles y publicaciones neonazis» que estuvieron activas desde julio de 1961 hasta agosto de 1962. Allí detalló que los incidentes antisemitas incluían amenazas, tatuajes de personas con esvásticas, quema de banderas de Israel, lanzamiento de bombas a sedes de instituciones judías y vandalismo contra los carteles de las calles que llevaban el nombre Estado de Israel. Las autoridades nacionales y la prensa condenaron públicamente los ataques y numerosas organizaciones y personas expresaron su solidaridad con los judíos. Destacadas figuras culturales y religiosas organizaron una asamblea en la Biblioteca Nacional para repudiar el antisemitismo. Estudiantes de secundaria y universitarios se declararon en huelga para expresar su solidaridad con los judíos uruguayos (Pilosof, 1964, 288-292; 289-290).

El hecho de haber sido precisamente la juventud la principal protagonista de estos incidentes racistas afectó profundamente a los judíos de primera generación nacidos en Uruguay. R. S. fue uno de ellos. Nacido en Montevideo en 1944, de padres originarios de Galitzia y criado en un hogar tradicional religioso en Montevideo, asistió a la escuela judía Yavne y participó activamente en los movimientos sionistas Dror y Hashomer Hatzair. Sus experiencias durante esos tiempos agitados crearon memorias para toda la vida. En ese entonces, solía llevar un cuchillo escondido en su bolso, para estar listo en caso de un ataque. Cuando estaba en el segundo año de preparatoria también fue con uno de sus amigos, Chito, a golpear a un compañero de clase que pintó «Juden Raus» (judíos, fuera, en alemán) en la pared de la escuela. El hecho de que el destinatario de la paliza estuviera con toda su pandilla no lo hizo retroceder. Con 
orgullo me contó: «Éramos dos contra veinte». ${ }^{24} \mathrm{Al}$ día siguiente estuvo a punto de ser expulsado de la escuela, pero su director, Hugo Fernández Artucio, un intelectual antifascista y autor de los libros Nazis en Uruguay (Buenos Aires, 1940) y The Nazi Underground in South America (Nueva York, 1942), intercedió a su favor.

\section{Betar Uruguay: el liderazgo en las iniciativas de la autodefensa judía}

Betar en Montevideo fue establecido en 1932 por inmigrantes judíos de Europa oriental. En el período posterior a la Segunda Guerra Mundial se convirtió gradualmente en un importante movimiento juvenil sionista y en la fuerza principal de las iniciativas de autodefensa. En los años sesenta fue reconocido como tal incluso por los movimientos sionistas socialistas. Parece que muchos jóvenes judíos -de todos los matices políticos e ideológicos- tanto en los Estados Unidos como en América del Sur se vieron muy influidos por el pensador revisionista Vladimir (Ze'ev) Jabotinsky, que durante los primeros decenios del siglo xx advirtió de los peligros a que se enfrentaban los judíos en la diáspora y pidió que se estableciera un Estado judío soberano en Palestina. Imaginó un nuevo tipo de judío: orgulloso, generoso y feroz (Shindler, 2009, 116-132). Nacido en Odessa en 1880, fue uno de los fundadores de la organización de autodefensa judía en esa ciudad ucraniana en 1903. A medida que aumentaban las posibilidades de nuevos pogromos, el grupo de autodefensa se propuso proteger a las comunidades judías en otras partes de la Rusia Imperial (Lambroza, 1987, 253-274).

Junto con Iosef Trumpeldor, Jabotinsky fue cofundador de la Legión Judía que se acopló al ejército británico para combatir en la Primera Guerra Mundial contra el imperio otomano, que gobernaba entonces Palestina. Después de dado de baja en septiembre de 1919 comenzó a capacitar a judíos en técnicas de combate y el uso de armas cortas en Palestina. Jabotinsky falleció por un ataque cardíaco el 3 de Agosto de 1940, durante una visita a un campo de entrenamiento de autodefensa judía en Hunter, en estado de Nueva York, que era activado por Betar, el movimiento juvenil revisionista

\footnotetext{
${ }^{24}$ Entrevista del autor con R. S., Hertzliya, junio de 2019. Sobre las movilizaciones estudiantiles, ver Vania Markarian. Uruguay, 1968: Student Activism from Global Counterculture to Molotov Cocktails. (Oakland, California: University of California Press, 2017); María Eugenia Jung, «La Universidad de la Repúbica como enemigo interno: la reacción de las derechas uruguayas, 1958-1973», Anuario IEHS 32/2 (2017): 149-170.
} 
que fundó en Riga, Letonia, en 1923. ${ }^{25}$

Menajem Beguin, el colaborador más cercano de Jabotinsky, continuó la trayectoria de este último, a través del Irgún Tzvaí Leumí (conocido por sus iniciales en hebreo, Etzel), que luchó contra el dominio británico en Palestina a mediados de la década de 1940. El libro de Begin sobre dicha lucha fue traducido al español y publicado en Buenos Aires en 1951, con una carta manuscrita del autor a los lectores argentinos, coincidiendo con una visita suya (Begin, 1951). A pesar de que Jerut, el partido político que Begin encabezaba, siguió siendo minoría en las instituciones comunitarias, su líder y su combate contra los británicos fascinó a muchos jóvenes judíos sudamericanos. Begin también visitó la región más que cualquier otro político israelí de la primera línea. En setiembre de 1962 volvió a una gira por esos países y en un discurso en Río de Janeiro llamó específicamente a la juventud judía del Cono Sur a formar unidades de autodefensa «como respuesta efectiva a los hooligans antisemitas», utilizando «todos los medios necesarios a su disposición», una cita que utilicé para titular este artículo. ${ }^{26}$ Este mensaje fue repetido en un encuentro que mantuvo en Montevideo con 33 líderes comunitarios, en su mayoría del movimiento Betar y del partido Jerut, en el que estuvo presente el embajador Harkavi. ${ }^{27}$ No es casual que para entonces los grupos de defensa judíos en Argentina adoptaron como nombre el Irgún[ (la organización). Pero allí fueron los sionistas socialistas quienes asumieron el papel principal en la autodefensa de los judíos; en Montevideo, en cambio, fueron los sionistas revisionistas de Betar quienes llevaron la voz cantante.

El testimonio de Samuel Hendel destaca el activismo de Betar en Montevideo desde sus comienzos. Nacido en Galitzia en 1923, llegó con su familia a Uruguay en 1928. A la edad de 15 años se unió a la rama local de Betar. En los años siguientes se convirtió en una figura prominente del partido Revisionista Sionista local, así como de la comunidad judía organizada, llegando a ser presidente del Comité Central Israelita del Uruguay en 1974. Al relatar sobre los últimos años de la década de 1930 y comienzos

\footnotetext{
${ }_{25}$ Para una biografía reciente del líder revisionista, ver Hillel Halkin, Jabotinsky: A Life. (London: Yale University Press, 2014). Véase también Eran Kaplan, The Jewish Radical Right: Revisionist Zionism and Its Ideological Legacy. (Madison: University of Wisconsin Press, 2005).

26 «M. Begin llama a la juventud judía en América del Sur a organizar autodefensas», [en hebreo] Herut [Tel Aviv], set. 10, 1962: 1.

27 Entrevista del autor con Aida Stoler vía Zoom, abril de 2020.
} 
de la de 1940, recordó:

Hacíamos también toda clase de ejercicios paramilitares, práctica de tiro por ejemplo. Eso fue antes de la Guerra [mundial]. Teníamos un fondo grande y ahí practicábamos tiro. Empezábamos a practicar la autodefensa y algunos de los sistemas de lucha japonesa (Hendel, 90-92).

Resulta curioso que Betar no sólo fue el pionero en inculcar la idea de la autodefensa judía y la necesidad de enfrentar el antisemitismo originado en los nacionalistas de la extrema derecha, sino también en considerar a los uruguayosárabes como una amenaza potencial para la vida judía en el país. Hendel dice:

Intervinimos también por el año 47 contra algunos brotes de actividad de los libaneses. Hacían algunas manifestaciones, sobre todo cuando los judíos se reunían en sus actos del Ateneo. Aparecieron en más de una oportunidad para entorpecer la actividad. Era gente de la Sociedad Libanesa, en la calle Colonia. Salían en actos callejeros, pasaban con un auto y gritaban. Pero a la prensa no salieron (Hendel).

Desde el punto de vista numérico, Betar nunca fue el principal movimiento juvenil sionista de Uruguay, pero su influencia ideológica fue mucho más allá del aspecto cuantitativo de sus afiliados.

\section{El caso Cukurs}

Poco después de la ejecución de Eichmann en Israel, otro criminal nazi fue expuesto en Brasil. Su destino, sin embargo, se sellaría en un suburbio de Montevideo el 23 de febrero de 1965. Herberts Cukurs había sido un héroe de la aviación durante el decenio de 1930 en su país natal, donde lo apodaban el Charles Lindberg letón. Durante la Segunda Guerra Mundial desempeñó un papel destacado en la masacre de los judíos de Riga y cometió personalmente atrocidades espantosas (Angrick y Klein; 2009). Entre los crímenes que le fueron atribuidos por los testimonios de los supervivientes se encuentra la matanza de trescientos judíos calcinados vivos en una sinagoga que fue incendiada, el ahogamiento de 1200 judíos en el lago Kuldiga durante el invierno y, finalmente, en noviembre de 1941, el haber llevado a treinta mil judíos de Riga a los bosques, donde fueron desnudados y fusilados por soldados alemanes. Con ello se ganó también el apodo menos simpático de el carnicero de Riga.

Finalizada la guerra, huyó a Brasil a través de Francia, usando para ello a una mujer judía, a la que había protegido durante la contienda, entre otras cosas para crear una historia de cobertura como salvador de judíos. Cukurs se asentó primero en Río de 
Janeiro y consiguió atraer la simpatía de judíos brasileños. ${ }^{28}$ Cuando los rumores sobre sus atrocidades en tiempos de guerra comenzaron a extenderse, tuvo que alejarse. Durante un período de diez años logró vivir tranquilamente, ganándose la vida con la explotación de un puerto turístico de embarcaciones y un viejo hidroavión, hasta que fue expuesto públicamente por las organizaciones judías brasileñas que organizaron varias manifestaciones en su contra (Bar Zohar y Mishal, 2012 11).

Las peticiones para que fuera expulsado del país fueron rechazadas debido a «insuficiencia de pruebas». Israel también consideró la posibilidad de solicitar su extradición. ${ }^{29}$ Tras el secuestro de Eichmann, Cukurs cobró conciencia del peligro que corría su vida y pidió protección al gobierno brasileño y permiso para portar un arma. 30 Le fue asignada una custodia de seis policías, pero su pedido de naturalización fue rechazado por el presidente brasileño Juscelino Kubitchek. ${ }^{31}$

Durante la primera mitad de la década de 1960, el gobierno de la República Federal Alemana tuvo que tomar una decisión con respecto al enjuiciamiento de los actos perpetrados por los nazis, ya sea poniendo fin a las investigaciones de los crímenes de guerra debido a la prescripción de los actos de homicidio y asesinato, o encontrar la manera de dar a los fiscales tiempo adicional para reunir pruebas e iniciar procedimientos contra los restantes sospechosos. El punto límite prescrito para juzgar actos de los nazis, el 8 de mayo de 1965, se convirtió en el fruto de la discordia en las relaciones bilaterales con Israel. En 1964, el Primer Ministro Levi Eshkol y el general Meir Amit, jefe del Mossad, pensaron que la captura de otro criminal de guerra importante presionaría a los legisladores alemanes para votar a favor de la continuación de los procedimientos legales contra los sospechosos de haber cometido crímenes de guerra y para que «grupos de voluntarios» no se encargaran de eliminar a estos criminales fuera de todo marco legal. $3^{2}$ Amit encargó al agente del Mossad Yaakov

\footnotetext{
${ }_{28}$ Anton Künzle and Gad Shimron. The Execution of the Hangman of Riga: The Only Execution of a Nazi War Criminal by the Mossad. (Hertfordshire: Mitchell Vallentine \& Co, 2004), 45. Ver también Stephan Talty, The Good Assassin: How a Mossad Agent and a Band of Survivors Hunted Down the Butcher of Latvia. (Nueva York: Houghton Mifflin Harcourt, 2020).

29 «El Ministro de Justicia revisa una solicitud del miembro de la Knesset Nurock de demandar la extradición del exterminador de los judíos letones», [en hebreo] Herut [Tel Aviv], sep. 1, 1960. 30 'After Eichmann Capture Latvian War Criminal in Brazil Wants Protection', The Sentinel [Milwaukee], jun. 30, 1960: 3. 'Urge Brazil Deport Latvian', Bnai Brith Messenger [Los Angeles], dec. 16, 1960: 5.

${ }_{31}$ 'Former Nazi', Bnai Brith Messenger [Los Angeles], 22.7.1960, p. 23;'Brazil Says No to Ex-Nazi's Bid', The Sentinel [Milwauke], oct. 20, 1960: 3.

${ }^{32} \mathrm{Al}$ final de la Segunda Guerra hubo, efectivamente, iniciativas de este tipo; ver Dina Porat, The Fall of
} 
Meidad eliminar a Cukurs. Meidad viajó a Brasil, haciéndose pasar por un hombre de negocios austríaco llamado Anton Kunzle, y logró ganarse la confianza de Cukurs con promesas de involucrarlo en grandes inversiones en proyectos turísticos en América del Sur.

Hubo varios elementos que diferenciaron entre la operación para secuestrar a Eichmann y la realizada para eliminar a Cukurs: el primero forjó una falsa identidad bajo el nombre de Ricardo Klement y permaneció en las sombras; el segundo, en cambio, nunca ocultó su identidad y se convirtió en un blanco más fácil. Al mismo tiempo, la presión para expulsar a Cukurs hizo que tanto él como las fuerzas de seguridad brasileñas estuvieran en alerta. Otra complicación para el Mossad fue el hecho de que la pena capital estaba vigente en Brasil, por lo que sus agentes correrían un grave peligro en caso de que la misión fracasara. Una consideración adicional estaba relacionada con el hecho de que se consideraba que la comunidad judeo-brasileña podía quedar expuesta a las venganzas de neonazis. En ese sentido, el Uruguay democrático ofrecía un teatro de operaciones más conveniente. El Mossad evaluó que la comunidad judía local estaba menos expuesta a la violencia y vio una ventaja en el hecho de que en ella no existía la pena de muerte.

Atraído por un proyecto empresarial, Cukurs viajó al Uruguay y fue llevado por Meidad a una casa en un suburbio alejado de Montevideo. Tras una corta y violenta lucha con un grupo de agentes del Mossad, le dispararon dos veces en la cabeza y su cuerpo fue metido en un baúl con una nota en inglés explicando las razones de su asesinato. A raíz de una información enviada a una agencia de noticias en Alemania Occidental por un grupo identificado como «Los que nunca olvidarán», la policía uruguaya encontró el cuerpo de Cukurs varios días después.33 La policía se refirió a un «acto de venganza judía» y la prensa informó que «un empleado del gobierno israelí estuvo involucrado en el asesinato de Herberts Cukurs».34 Sin embargo, el portavoz del Ministerio de Relaciones Exteriores israelí declaró que dicha versión era «infundada»

the Sparrow: The Life and Times of Abba Kouner. (California: Stanford University Press, 2009).

33 Ver el informe de la Policía de Montevideo, Dirección de Investigaciones, Departamento de Inteligencia y Enlaces, «Memoria anual de Investigaciones y Enlaces Año 1965»: 156. Quiero agradecer a Magdalena Broquetas por compartir conmigo este documento.

34 «Police Charge Cukurs Murder Suspect Is Employee of Israeli Government», The Sentinel [Milwaukee], mar. 18, 1965: 5; «Una organización de vengadores antinazis en Uruguay eliminó a Cukurs, el asesino de judíos letones», [en hebreo] Ma'ariv [Tel Aviv], mar. 7, 1965; «El comando israelí ejecutó al criminal nazi Cukurs», [en hebreo] Lamerchav [Tel Aviv], mar. 8, 1965. 
y poco después el gobierno uruguayo se disculpó por las acusaciones.35 Por su parte, la policía uruguaya anunció que no tenía ninguna pista sobre los autores de este asesinato y que no había ningún daño en las relaciones uruguayo-israelíes. ${ }^{36}$

Cukurs fue el único criminal de guerra nazi asesinado por el Mossad. El objetivo de la operación fue alcanzado y la República Federal Alemana decidió continuar investigando y sometiendo a juicio a sospechosos de haber cometido crímenes de lesa humanidad. Como en el caso de la captura de Eichmann en Buenos Aires, el Mossad no pudo haber eliminado a Cukurs sin ayuda local de judíos uruguayos. Su papel en lo que llamaron «nuestro caso Eichmann» es insinuado a menudo, pero nunca se discute explícitamente,37 ya sea para glorificar al Mossad o para no provocar pretextos adicionales para ataques antisemitas.

Sin dudas, el asesinato de Cukurs fue el disparador de otra ola de incidentes antisemitas en Montevideo, similares a los que siguieron a la captura de Eichmann. 38 Una vez más, el deterioro económico de ese año, la caída de los salarios reales, el aumento del desempleo y el colapso del sistema bancario contribuyeron a cierto malestar social. Se hicieron disparos contra una sinagoga y una bomba explotó en otra, causando daños menores. Hubo un ataque contra la Sociedad Hebraica Macabi en la calle General Máximo Tajes, proliferaron pintadas de cruces gamadas y de graffiti en las paredes, y llamadas telefónicas anónimas amenazaban a los líderes comunitarios con la muerte o advirtiendo sobre el lanzamiento de bombas contra templos u otras instituciones. ${ }^{39}$ Se enviaron paquetes sospechosos a judíos. El dueño de una tienda recibió una caja de madera que afortunadamente no explotó y otro recibió una cartabomba. $4^{0} \mathrm{El}$ remitente fue identificado como Everildo Héctor Díaz Santos, quien tenía

\footnotetext{
35 «Una disculpa formal por las acusaciones», [en hebreo] Lamerchav [Tel Aviv], mar. 11, 1965.

36 «La Policía del Uruguay dejó de investigar el caso Cukurs», [en hebreo] Lamerchav [Tel Aviv], mar. 11, 1965; "La Policía uruguaya cerró el expediente Cukurs y lo envió a Interpol», [en hebreo] Hatzofé [Israel], mar. 11, 1965.

37 Ver, por ejemplo, Dan Raviv and Yossi Melman. Spies Against Armageddon [en hebreo]. (Tel Aviv: Yedioth Aharonot, 2012), 131-133 (hay versión inglesa. Sea Cliff: Levant Books, 2014). Gustavo Kronenberg recuerda, como niño de siete años, las reunions secretas en su hogar en vísperas del asesinato de Cukurs.

38 «Brasas antisemitas chisporrotean en Montevideo», [en hebreo] Herut, 10.3.1965; «Los judíos uruguayos están preocupados por el futuro», [en hebreo] Al Ha-Mishmar, 21.3.1965.

39 «Tres órdenes de arresto emitidas en Uruguay tras la eliminación de Cukurs - Nadie resultó detenido», [en hebreo] Ma'ariv, 8.3.1965; 'Bomb Synagogue in Montevideo', The Sentinel, 11.3.1965, p. 5; «Nazis en Montevideo disparan contra una sinagoga», [en hebreo] Kol Ha-Am, 11.3.1965.

40 «Una bomba fue enviada en una caja de madera a un judío en Uruguay», [en hebreo] Herut [Tel Aviv],
} 
vínculos con Tacuara (Broquetas, 2014 236).

El Comité Central Israelita atribuyó la responsabilidad de estos atropellos a lo que caracterizaron como un grupo nazi clandestino pequeño pero virulento, denunciando que tenía conexiones con movimientos nazis en el extranjero y que contaba con la ayuda de la Liga Árabe. ${ }^{11}$ Aunque los judíos de Uruguay parecían estar en una posición más segura que años atrás, la organización de autodefensa no cesó sus actividades. Sus objetivos ahora incluían no sólo a grupos antisemitas de extrema derecha, sino también a grupos de la pequeña comunidad uruguaya-árabe -en Montevideo, Chuy y Rocha- o grupos apoyados por la Liga Árabe. ${ }^{42}$ Los grupos espontáneos de autodefensa de principios de los años sesenta también se convirtieron en esta etapa en una organización bien estructurada y jerárquica con una colaboración más estrecha con la comunidad judía organizada, por un lado, y con la embajada de Israel, por otro. En sus inicios, la principal tarea de la organización era brindar protección a los movimientos juveniles judíos, las instituciones comunitarias, la embajada de Israel y a visitantes israelíes. Sin embargo, pronto comenzó un reclutamiento más sistemático y programas de capacitación bien preparados, emulando en parte la experiencia argentina.

Los miembros de la organización fueron entrenados en Krav Maga, [en hebreo: lucha de contacto], un arte marcial desarrollado en Israel, que prepara a la gente para luchar contra uno o más atacantes e incluye una variedad de técnicas que utilizan el cuerpo, así como cuchillos, hachas, bastones, piedras y botellas. También incluye técnicas para desarmar a los atacantes que llevan armas de fuego. A lo largo de los años, los judíos uruguayos se entrenaron en la sede de la Sociedad Hebraica Macabi en Carrasco, en los bosques de las afueras de Montevideo y en un campamento en Colonia. En algunos casos, especialmente a partir de finales de los años sesenta, lo hicieron en Macabilandia, el principal lugar de capacitación de los grupos de autodefensa argentinos, en la provincia de Córdoba. Un número menor recibió entrenamiento

\footnotetext{
mar. 19, 1965 .

41 'Uruguay', en American Jewish Yearbook. (Nueva York: American Jewish Committee, 1967), 306308.

${ }^{42}$ La mayor parte de los uruguayos-árabes eran de ascendencia libanesa y cristianos, con una minoría de musulmanes. Por aquel entonces, uno de ellos, Alberto Abdala, fue vicepresidente de la República (1967-1972). Ver Renzo Pi Hugarte, «Asimilación cultural de los siriolibaneses y sus descendientes en Uruguay», Anuario de Antropología Social y Cultural en Uruguay (2005): 53-58.
} 
adicional en Israel.43 $\mathrm{Al}$ mismo tiempo, miembros de grupos de autodefensa judíos de la Argentina, Venezuela, Paraguay, Brasil, Chile y Perú vinieron a entrenarse en el Uruguay. «Teníamos una red latinoamericana de autodefensa judía».44

Como en el caso argentino, la autodefensa judía en Uruguay se caracterizó por su organización jerárquica que incluía un pequeño grupo de líderes, algunos de los cuales recibían un salario mensual. Los voluntarios han sido la columna vertebral de la organización, y en general eran jóvenes de entre 17 y 24 años. Los dirigentes que percibían un salario eran generalmente mayores y con varios años de capacitación. Por lo general, eran los únicos miembros de la organización que portaban armas de fuego. El proceso de reclutamiento entre los jóvenes judíos en las escuelas secundarias y los movimientos juveniles sionistas era en su mayoría secreto. En una primera reunión, dos reclutadores solían explicar los compromisos que cada miembro asumía al sumarse a la organización y las características de los entrenamientos. Si la persona daba su consentimiento, se la contactaba para una capacitación inicial. Los dos primeros años de preparación física y teórica eran clave para determinar si una persona podía convertirse en miembro permanente de la organización. Hombres y mujeres se entrenaron en igualdad de condiciones en situaciones que simulaban una violencia real y todo se llevaba a cabo bajo un estricto secreto. Ni siquiera la familia debía saber sobre la participación del miembro en la autodefensa. Según el testimonio de un ex miembro, incluido en el libro de Fernando Amado, la suya fue una vivencia religiosa. Otra persona, un exlíder de la comunidad, le dijo a Amado - un politólogo y político- que en algunas ocasiones, durante sus entrenamientos, una persona resultó herida y fue necesario que ese líder ofreciera una explicación a los padres (Amado, 2012 268).

\section{El desplazamiento de la mira a las actividades árabes en Montevideo}

Una fuente importante de preocupación para las comunidades judías organizadas del Cono Sur a lo largo de la década de 1960 fue el aumento de la propaganda antisionista y antisemita difundida por la embajada de la Liga Árabe. Esta tenía su sede en Buenos Aires y su director hasta mediados de la década fue el tunecino Hussein Triki. La campaña fue entonces dirigida por diplomáticos árabes de varios

43 Entrevista del autor con C. G, abril de 2020.

44 Ídem 
países, especialmente después de su derrota por las fuerzas armadas israelíes en la Guerra de los Seis Días de 1967. Los representantes árabes establecieron alianzas y colaboraciones con organizaciones nacionalistas de extrema derecha en ambos países, como Tacuara y la Guardia Restauradora Nacionalista en Buenos Aires (ambas recibieron apoyo financiero para sus publicaciones) o FEDAN y Montonera en Montevideo. También trataron de movilizar el apoyo de los argentinos-árabes y de los uruguayos-árabes para sus campañas contra Israel. Artículos que salieron en el mensuario Nación Árabe se reeditaron en publicaciones periódicas nacionalistas en ambas orillas del Río de la Plata. 45

En Buenos Aires, Triki trató de alertar al público de las actividades de autodefensa de los judíos, advirtiendo que «unos veintiséis campos de entrenamiento para personal militar israelí están operando en territorio argentino, e incluso el idioma español está prohibido allí».46 Según una de las personas que entrevisté, Triki dejó la ciudad después de que el Irgún prendió fuego a las oficinas de la Liga Árabe allí, que se encontraban en un primer piso, al frente. La operación comenzó en forma coordinada con un grupo que bloqueó el tráfico en la zona, otro grupo que lanzó cócteles molotov y un tercer grupo que transmitió un mensaje a Triki amenazándolo de muerte si no abandonaba Buenos Aires. 47 De hecho, Triki fue declarado persona non grata por el gobierno del presidente Arturo Illia en 1965, acusado de inmiscuirse en asuntos internos de la Argentina y de violar las leyes antidiscriminatorias. Poco tiempo después abandonaba el país. $4^{8}$ Otro ataque contra las oficinas de la Liga Árabe en Buenos Aires tuvo lugar en 1970.49

La Guerra de los Seis Días encontró un eco inmediato en la respuesta de muchos judíos en Uruguay, como en muchos otros lugares. La victoria israelí despertó un gran

\footnotetext{
45 Michael Goebel, «Von der Hispanidad zum Panarabismus», Geschichte und Gesellschaft 37/4 (2011): 523-558; Andrés Kilstein, «Vínculo entre sectores del peronismo de derecha y la Liga Árabe en la Argentina entre 1962-1964", ponencia presentada en el 2. ${ }^{\circ}$ Congreso de Estudios sobre el Peronismo (1943- 1976), UNTreF, Nov. 2010; Leonardo Senkman, El antisemitismo en la Argentina. (Buenos Aires: CEAL, 1986): vol. 1, 52-53.

46 Citado en Yehuda Adín, «Nacionalismo y Neonazismo en Argentina,» [en hebreo] Betfutzot Hagola 7, no. 33 (1965): 77. Con respecto a Triki, sus ideas y sus actividades, ver Hussein Triki, He aquí Palestina... El sionismo al desnudo (Madrid: Afrodisio Aguado 1977).

47 Entrevista del autor con H. P., Buenos Aires, julio de 2014.

48 «Argentina Talks of Ousting Arab», New York Times, ago. 9, 1964: 9; La Nación [Buenos Aires], abr. 5, 1965; La Prensa [Buenos Aires], jul, 1, 1965.

49 «Atentado en la oficina de la Liga Árabe», La Nación [Buenos Aires], feb. 28, 1970.
} 
entusiasmo entre los judíos de la diáspora y fortaleció su confianza en sí mismos, así como la identidad sionista de muchos de ellos. Muy pocos eventos desde el Holocausto tuvieron un efecto tan galvanizador en la comunidad judía uruguaya. Excepto en el sector comunista, todas las organizaciones judías se unieron para apoyar la causa de Israel. Además, las personas que habían permanecido alejadas de la vida comunitaria se sentían atraídas por las instituciones judías. La recaudación de fondos y la movilización política aumentaron considerablemente. Alrededor de doscientos voluntarios, muchos de ellos con alguna experiencia previa en actividades de autodefensa, viajaron a Israel cuando estalló la guerra. La mayoría de ellos regresaron al cabo de seis meses, pero hubo un aumento de la emigración a Israel. Chaim Sivan tenía 17 y medio años cuando estalló la guerra y figuraba entre los voluntarios que viajaron. A su regreso a Montevideo, fue reclutado por la organización de autodefensa. Sin embargo, Sivan sólo tuvo un par de sesiones de entrenamiento, ya que ya tenía planes de concretar su «aliá» (emigración a Israel) y de hecho lo hizo en 1969.50 En cualquier caso, según los demógrafos, en 1967 el mayor apoyo a Israel llegó desde las comunidades judías de tamaño medio de Europa Occidental, con una tasa combinada de 8,4 voluntarios que viajaron a Israel por cada mil judíos. Luego vino Uruguay con 6,9 voluntarios por cada mil judíos, muy por delante de otros países americanos, incluyendo Argentina (1,9), y los EEUU y Canadá (con sólo 0,2 voluntarios por cada mil habitantes judíos). ${ }^{1}$

Emanuel Adler, que nació en Montevideo en 1947, fue uno de los participantes en las actividades de autodefensa. Recordando aquellos tiempos y sonriendo, declaró: «Yo fui un simple soldado». Explicó que los voluntarios de autodefensa en Uruguay estaban divididos en dos grupos, $I$ de inteligencia y $D$ de defensa. Como estaba en el primer grupo, nunca participó en acciones físicas o violentas. Su tarea, después de la Guerra de los Seis Días, consistió en vigilar las actividades de algunos uruguayos de origen árabe

Emanuel había sido un miembro activo del movimiento juvenil Macabi, uno de

\footnotetext{
50 Entrevista del autor con C.S., abril de 2020.

${ }^{51}$ Sergio DellaPergola, Uzi Rebhun, and Rosa Perla Raicher. «The Six-Day War and Israel-Diaspora Relations: An Analysis of Quantitative Indicators», The Six-Day War and World Jewry. ed. Eli Lederhendler (Bethesda, MD: University Press of Maryland, 2000), 11-50, 34. Sobre voluntarios orientales y argentinos, ver El Mundo [Bs.As.], jun. 9 y 10, 1967; La Razón [Buenos Aires], jun. 9 y 10, 196; Clarín y La Prensa [Buenos Aires], jun. 10, 1967.
} 
los dos mayores movimientos juveniles sionistas de Montevideo en ese momento y el que más énfasis puso en la educación física y los deportes. Había pasado un año en un kibutz en Israel, pero no recibió ningún entrenamiento significativo para sus deberes de inteligencia. Añadió: «Nos mandaban a restaurantes mesorientales para pedir humus y entablar conversaciones con la gente que se sentaba en otras mesas. A veces seguíamos a las personas que entraban o salían de ciertas oficinas o casas privadas y confeccionábamos listas completas de ellas». Sonriendo nuevamente dijo que en la comunidad judía de Uruguay «era un honor [usó la palabra en ídish yijes] ser parte de la organización de la autodefensa».52 Miembros sefardíes de la Misgueret, provenientes de la Agrupación de la Comunidad Israelita Sefaradí del Uruguay (AJISU) lograron infiltrarse en grupos árabes. Adler repitió los testimonios de otras personas en cuanto a la participación de la representación diplomática israelí en Montevideo en sus actividades: «de hecho, todo fue manejado por la embajada».53

Entre 1966 y 1973, la figura clave de la autodefensa judía fue Julio Ring. Nacido en Montevideo en 1944 en una familia de clase media baja, su padre había sido miembro de Betar en Polonia, antes de emigrar al Uruguay. Fue «natural» que Julio se uniera a Betar en Montevideo poco después de su bar mitzvá, convirtiéndose gradualmente en Madrij (instructor), miembro de la junta nacional y Mefaked (comandante) del Campamento Continental en 1961, una actividad conjunta de las diferentes representaciones de Betar en América Latina. Para entonces ya era miembro de los grupos de autodefensa. En 1963 la familia emigró a Israel, donde Julio participó en actividades del movimiento revisionista y se convirtió en asistente del ex miembro del Etzel, Ben Zion Guivony. Comenzó su servicio militar en la fuerza aérea israelí y lo completó en 1966. Luego regresó al Uruguay para estudiar medicina en la Universidad de la República. Basándose en su anterior activismo en Betar y su servicio militar en Israel, Ring fue designado para desempeñar un papel de liderazgo en la organización de autodefensa:

Inmediatamente después de llegar a Montevideo, mi primo [Mario Julio Yudka], quien sirvió como oficial de inteligencia en la Misgueret local, me puso en contacto con el agente del Mossad que trabajaba encubierto en la embajada israelí. Por un lado, la estación local se estaba desmoronando y era completamente dependiente de la de Buenos Aires; por otro lado, debido a un largo período de relativa paz, la Misgueret (compuesta por voluntarios) se caracterizaba por un nivel muy bajo de actividades de

\footnotetext{
$5^{2}$ Entrevista del autor con Emanuel Adler, Kineret College, junio de 2019.

53 Entrevista del autor con Adler, junio de 2019 y con A. S., abril de 2020.
} 
inteligencia y operativas. Mi propio primo estaba a punto de retirarse de su trabajo. Me ofrecieron ser la persona de contacto con [la estación de] Buenos Aires y ocuparme de los asuntos de inteligencia como oficial en un trabajo remunerado...

Así las cosas evolucionaron de tal manera que trabajé en tres niveles: a) operativo (fuerza de comando), organizando los primeros cursos [de capacitación] y consultando sobre la gestión de los diversos grupos; b) inteligencia, donde de hecho organicé las actividades de manera diferente, según unidades y escuadras de observación y vigilancia; recopilación de información de fuentes abiertas, infiltración en organizaciones hostiles, gestión de agentes, red de instituciones de capacitación, cursos, etc.; c) custodia de la embajada [israelí], ya que no había ningún oficial de seguridad, y en esta capacidad, especialmente cuando se preparaban las visitas [de israelíes], estaba en contacto con las fuerzas de seguridad locales. 54

Así pues, Ring (y sus sucesores) trabajaron desde la embajada israelí, colaboraron estrechamente con la comunidad organizada, especialmente a través de la Comisión de Prensa y Difusión del Comité Central Israelita (COPREDI), y estuvieron en contacto con la policía y los servicios secretos uruguayos para evitar enfrentamientos innecesarios. Aun así, «fuimos muy cuidadosos en nuestro trato con la policía ya que no siempre estábamos seguros de las inclinaciones ideológicas de los oficiales con los que estábamos en contacto».55

Otro primo de Julio, Miguel Ring, tuvo una trayectoria algo similar. A los 14 años también era miembro de Betar ( «Me enviaron a Betar, no había ninguna duda al respecto», me cuenta sonriendo). En 1963 también él llegó a Israel, hizo el servicio militar al mismo tiempo que Julio (1964-1966) y a principios de 1967 volvió también él a Montevideo. Al año siguiente fue contratado por Julio para trabajar en la embajada israelí: «Julio era el oficial de seguridad y encargado de la sección consular. Aida Stoler dejó su puesto y Julio me ofreció el trabajo... La oficina de Julio estaba en el último piso».56 Pareciera que toda la familia Ring estaba involucrada en estas actividades: Julio, su esposa Irene que a veces le ayudaba a escribir informes, su hermano que estaba en el ala de Defensa, y sus dos primos, Mario Julio Yudka y Miguel.

Aunque los signos de antisemitismo habían tendido a desvanecerse desde las campañas que siguieron a los asuntos de Eichmann y Cukurs, la efervescencia política regional que había puesto a los estudiantes en el centro del activismo político y la radicalización pronto encontraría un canal antisemita para una parte de ellos en el

\footnotetext{
54 Currículum Vitae manuscrito de Julio Ring entregado al Mossad en 1974.

55 Entrevista del autor con C. G, abril de 2020.

${ }^{56}$ Entrevista del autor con Miguel Ring, Givataim, julio de 2019.
} 
Uruguay. Según el testimonio de personas que participaron en la autodefensa judía a principios de la década de 1970, una de las principales fuentes de preocupación en ese momento fue la Juventud Uruguaya de Pie, conocida como JUP. La JUP era un grupo de derecha que apareció en la escena política como reacción al surgimiento del Movmiento de Liberación Nacional-Tupamaros (MLN-T) y otros grupos de izquierda. Estaba integrada por militantes anticomunistas que querían revitalizar los valores tradicionales de la sociedad oriental. Fue mucho más que una agrupación juvenil y movilizó apoyo en varios sectores de la sociedad, sobre todo en el interior del país. Algunos de ellos promovieron la idea de una revolución nacional de características falangistas. La organización estuvo activa desde 1970 y dos años más tarde comenzó a participar en la violencia paramilitar que precedió al régimen militar. La JUP se disolvió en 1974 (Bucheli, 2019).

Julio Ring conoció a su futura esposa, Irene, en marzo de 1971, en una sesión de reclutamiento de nuevos miembros para la Orga. Ella era miembro de Macabi. Tras un entrenamiento en los bosques de las afueras de la capital, fue puesta a cargo de actividades de vigilancia.57 Una de sus misiones era ir con amigos a una zona rural, donde la JUP estaba organizando una manifestación. Se suponía que el escuadrón judío debía fotografiar a los participantes. Una vez que llegaron a la aldea, la policía los detuvo y tuvieron que pasar la noche en la comisaría local. Irene llamó a su padre para pedirle ayuda. «Mi abuelo tenía conexiones con la policía local y las usó más de una vez», me dice Idán, el hijo de Julio e Irene. $5^{8}$ La Misgueret recibió información sobre las actividades de la JUP de parte del oficial de seguridad de la Facultad de Medicina, que estaba estrechamente vinculado a los nacionalistas. «Sabíamos todo sobre ellos», me dijo un ex miembro de la autodefensa judía.

$\mathrm{Al}$ igual que otros judíos latinoamericanos que participaron en la autodefensa, también Julio Ring tuvo su parte de capacitación en el sótano de Macabi en Buenos Aires, bajo la dirección de Tata Furmanski, Pero ese año, 1971, estuvo también seis meses en un programa de entrenamiento en Israel, antes de regresar a Montevideo a las actividades de autodefensa y a la embajada israelí.

En 1970, cuando la JUP comenzó sus actividades, R. S. ya participaba en la

\footnotetext{
57 Entrevista telefónica del autor con Irene Treibich, abril de 2020.

${ }^{8} 8$ Entrevista del autor con Idan Ring, Tel Aviv, julio de 2019.
} 
organización judía de autodefensa. Participó en tres operaciones violentas: «quemamos varias imprentas en el sur de Montevideo. Por la noche, les lanzamos bombas molotov y se incendiaron. Estas imprentas publicaban propaganda antisemita, como Mein Kampf u otros panfletos». Como estudiante de arquitectura, solía pasar por zonas de construcción en áreas remotas, así que siempre llevaba un arma con él. Según otro testimonio, «estas actividades fueron bien planeadas y ejecutadas después de meses de preparativos».59 En un caso, «advertimos a una imprenta que dejara de vender literatura antisemita en su stand en una de las ferias de la ciudad. No nos escucharon, así que tuvimos que «hacernos cargo» de ellos».

R.S. también proporcionó protección a personalidades israelíes que llegaron en visitas, como Shlomo Lahat (ex general de las fuerzas de defensa de Israel y alcalde de Tel Aviv de 1974 a 1993) y Pinhas Sapir (ministro de finanzas de Israel, 1963-1974), con los que compartió cenas y largas conversaciones en inglés y en ídish. Recuerda haber conocido a Aliza y Menajem Beguin también en Montevideo.

Su principal tarea, sin embargo, era vigilar los alrededores de la embajada israelí en Montevideo y escoltar a las personas (por ejemplo, a los judíos que intentaban huir de Uruguay) desde la embajada hasta el aeropuerto o en el trayecto inverso. Solía sentarse en el asiento trasero de un coche con gente que estaba «armada hasta los dientes» y tenía órdenes de replicar fuego en caso de enfrentamiento. En una ocasión, esto casi sucedió:

... fuimos detenidos por la policía militar. Dos jeeps se interpusieron entre nuestros dos coches y nos encerraron. Salimos con nuestras armas en la mano. No sabíamos quiénes eran. [El embajador Dov] Shmorak salió rápidamente de su coche y le gritó a la policía que no disparara ya que éramos personal de la embajada. ${ }^{60}$

Al final de cada misión de este tipo, las armas quedaban depositadas nuevamente en la embajada israelí.

En 1973 Julio Ring y su familia se mudaron a Israel y la dirección de «la Orga» fue transferida a a Salomón Sapov primero y luego a Jaime G. Este último fue el jefe de la Misgueret durante un período más largo que cualquier otra persona, hasta el retorno de la democracia a principios de los años ochenta. Al igual que Ring, Jaime G. nació en

\footnotetext{
59 Entrevista del autor con C. G., abril de 2020.

6o Entrevista del autor con R.S, Hertzliya, junio de 2019.
} 
Montevideo en el seno de una familia de clase media baja y se unió a Betar, donde fue reclutado para actividades de autodefensa. Como Ring estudió en la Facultad de Medicina de la Universidad de la República, pasó parte de su entrenamiento en Buenos Aires y en Israel y tenía su oficina en la embajada israelí, «un arreglo que ya no existe».61

\section{Epílogo: el caso Paladino y una advertencia a todos los antisemitas}

El Uruguay estuvo gobernado por un régimen militar entre 1973 y 1985; el país había sido considerado hasta entonces como la nación más estable, libre y democrática de América Latina. Tras el golpe quedó sometido a un régimen autoritario represivo, a raíz de la crisis de sus instituciones democráticas, además de un fuerte declive económico, el aumento de la militancia entre los obreros industriales, el extremismo ideológico y el surgimiento del movimiento guerrillero urbano, los Tupamaros. Un líder de la comunidad declaró que la organización de autodefensa judía fue muy activa durante la dictadura con el fin de evitar que los elementos antisemitas utilizaran la sobrerrepresentación de los judíos en las organizaciones de izquierda para perjudicar a los judíos del Uruguay en su conjunto. Según un testimonio, es probable que haya habido casos de anuncios codificados en el periódico Semanario Hebreo, fundado en 1960 por José Jerozolimski, que transmitían mensajes a los miembros de la organización de autodefensa sobre la ejecución o la cancelación de determinadas actividades planificadas. ${ }^{62}$ La organización de autodefensa también trabajaba para alertar a los judíos perseguidos por las fuerzas de seguridad. Destacó que no había ningún vínculo entre la organización judía y estas fuerzas. Por el contrario, había miembros de la organización de autodefensa que fueron detenidos por las fuerzas de seguridad por estar involucrados en actividades «sospechosas».

El caso de Héctor José Paladino Ruvira, ocurrido durante la transición de Uruguay a la democracia, enseñó a la comunidad judía y a la organización de autodefensa una dura lección y resultó ser un punto de inflexión en sus actividades. Paladino había estado bajo estrecha observación por parte de la organización de autodefensa como un medio de intimidación, debido a sus actividades abiertamente antisemitas. Cuando se dio cuenta de que todos sus pasos eran vigilados, el conflicto

\footnotetext{
${ }^{61}$ Entrevista del autor por Skype con Jaime G., abril de 2020.

${ }^{62}$ Conversación del autor con E. N., Givataim, abril de 2020.
} 
sólo se intensificó. Pintó provocativamente «SS» en la fachada de su casa usando color rojo y la gente de Bitajón lanzó bombas de alquitrán para cubrir las pintadas. Paladino volvió a pintar las dos letras, usando color blanco sobre el asfalto (Amado, 270).

Mucha gente en Montevideo se había acostumbrado a ver una bandera nazi en el frente de la casa de Paladino. Sin embargo, casi nadie previó el desenlace cuando el 21 de diciembre de 1987 salió de su casa armado con una gran pistola y asesinó a Simón Lazovski, dueño de una mueblería, y de Delfino Sicco, director del Canal 4 de televisión. También hirió a Horacio Scheck cuando intentó matar a su padre, que era el director del Canal 12 y del periódico El País. Cuando Paladino se entregó a la policía, declaró que también había planeado asesinar a José Jerozolimski, director de la publicación judía de mayor difusión, Semanario Hebreo.63 Paladino fue sentenciado a reclusión, pero como se determinó que su salud mental estaba alterada, cumplió parte de su condena en el hospital Vilardebó. ${ }^{64}$

L. C. estaba entre aquellos que vigilaron la casa de Paladino, lo siguieron y escribieron informes quincenales sobre sus actividades. Nacido en Montevideo en 1967, había sido miembro activo de los movimientos sionistas Dror, Habonim y Jazit Ha-Noar desde los 14 años. Su primer entrenamiento en defensa personal fue durante un campamento de verano en Colonia, donde las niñas y los niños se entrenaban en grupos separados. Durante el primer ejercicio, cada chico tenía que golpear al que estaba a su lado y L. estaba al lado de uno muy fuerte y resistente. Los instructores eran los mismos que L. solía ver en las actividades regulares, pero durante el entrenamiento usaban diferentes nombres. En años posteriores, cuando él mismo se convirtió en un Madrij (instructor), su apodo sería Fernando. A los 15 o 16 años, L. y su grupo se encontraba una vez a la semana en la escuela judía por la noche y cada dos semanas entrenaban y practicaban «algunos golpes». Recordaba que se sentía «como James Bond». Había niños no judíos que solían lanzar cosas y gritarles insultos antisemitas desde un tejado junto a la escuela. Conscientes de la situación, los madrïim provocaban a L. y a sus amigos: «¿Cómo les permiten que les hablen así?» Los chicos

\footnotetext{
63 Entrevista telefónica del autor con Ana Jerozolimski, April de 2020; Ana Jerozolimski, «El Discurso Del Odio... y un recuerdo personal», Columnistas.Montevideo.Com.Uy, 2016. Web Consultado el 24 ago. 2019. http://columnistas.montevideo.com.uy/ucimprimir_301976_1.html.

64 «En 1987 Un Nazi Asesinó a Dos Personas y Se Entregó», El Observador, 2016. Web. Consultado el 24 ago. 2019. https://www.elobservador.com.uy/nota/en-1987-un-nazi-asesino-a-dos-personas-y-seentrego-2016310500.
} 
judíos decidieron esperar a que los niños bajaran del techo «y los cagamos a piñas». Después de este suceso, el conflicto parecía estar escalando. Un grupo muy grande de niños no judíos se reunió para volver y vengarse, «y de hecho llegaron cientos». Los niños judíos y sus instructores, con palos en la mano, estaban listos para luchar. Afortunadamente, los directores de la Escuela Integral lograron calmar a los dos bandos. 65

Un año después de los episodios mencionados, L. fue reclutado para trabajar en la rama de inteligencia de Bitajón y recibió capacitación por parte del oficial de seguridad de la embajada israelí. El mejor amigo de L. se convirtió en el Mefaked (comandante) de la rama operativa, después de capacitarse en Israel. L. tenía una persona de enlace en la comunidad judía que le asignaba tareas semanales. Por ejemplo, solía ir los domingos al mercado de Tristán Narvaja para observar los puestos de libros y ver quiénes eran las personas que vendían material antisemita o neonazi. También monitoreaba la mezquita local, prestando atención a los que entraban y salían del edificio. Participó en la protección de escuelas judías y dio protección a grupos de personas de una sinagoga durante visitas turísticas. En 1986 pasó un año en Israel, parte en el Majón le-Madrijim (un instituto de capacitación para instructores de movimientos juveniles sionistas en la diáspora) y cuatro meses en un kibutz. Durante ese período recibió instrucción de tiro y una vez de vuelta en Uruguay comenzó a trabajar para la embajada israelí como personal de seguridad local. L. explicó que sus actividades de autodefensa lo expusieron a la magnitud del antisemitismo en Uruguay. Nunca habló con sus padres sobre su papel en la autodefensa, pero su padre, nacido en Montevideo en 1937, le había dicho que cuando era joven y los judíos sufrían ataques, tomaban medidas espontáneas de autodefensa y algunos portaban un arma. L. caracterizó las actividades de autodefensa como «semisecretas», ya que los líderes de la comunidad judía las conocían, así como la embajada israelí. No podía decir si las fuerzas de seguridad lo sabían «pero sí, por supuesto, los tres policías destinados a la embajada israelí», porque practicaban junto con L. y sus colegas en el polígono de tiro. ${ }^{66}$

La organización de autodefensa uruguaya permaneció en su mayor parte

\footnotetext{
65 Entrevista del autor con L., Tel Aviv, marzo de 2019.
}

${ }^{66}$ Entrevista del autor con L., Tel Aviv, marzo de 2019. 
clandestina hasta mediados de la década de 1990. Sin embargo, tras el atentado contra el edificio de la AMIA tuvo que establecer nuevas relaciones con las fuerzas de seguridad locales. Nada cambió oficialmente y la organización no se mencionó en ningún informe o boletín oficial, pero en la práctica había un entendimiento mutuo con el Estado ahora. Desde 1994, el despliegue de Bitajón era visible en los operativos de seguridad organizados para recibir a personalidades israelíes, cuando se realizaban reuniones masivas de judíos para celebrar el Año Nuevo, el Día del Perdón o el acto para conmemorar a las víctimas de la Kristallnacht. Trabajaban en coordinación con la Policía y las Fuerzas Armadas. Un líder judío se refirió cómicamente a estas relaciones al recordar un diálogo entre el Ministro del Interior y el presidente de la comunidad judía durante una concentración masiva de personas. La policía y la autodefensa judía se encargaban de la seguridad y el Ministro, que quería enviar a uno de sus subordinados a comprar cigarrillos, señaló a un joven y preguntó al líder de la comunidad: «¿Aquel es tuyo o mío?» (Amado, 264).

\section{Obras citadas}

\section{Fuentes}

Entrevista del autor con E.N., Givataim, abril de 2020.

Entrevista del autor con Aida Stoler vía Zoom, abril de 2020.

Entrevista del autor con C. G., abril de 2020.

Entrevista del autor con C.S., abril de 2020.

Entrevista del autor con Emanuel Adler, Kineret College, junio de 2019.

Entrevista del autor con H. P., Buenos Aires, julio de 2014.

Entrevista del autor con Idan Ring, Tel Aviv, julio de 2019.

Entrevista del autor con L, Tel Aviv, marzo de 2019.

Entrevista del autor con Miguel Ring, Givataim, julio de 2019.

Entrevista del autor con R.S, Hertzliya, junio de 2019.

Entrevista del autor por Skype con Jaime G., abril de 2020.

Entrevista telefónica del autor con Ana Jerozolimski, April de 2020;

Entrevista telefónica del autor con Irene Treibich, abril de 2020.

Entrevista telefónica del autor con Gustavo Kronenberg, abril de 2020.

\section{Publicaciones periódicas}

The Sentinel [Milwaukee, 1960-1965] 
Bnai Brith Messenger [Los Ángeles, 1960]

La Mañana [Montevideo, 1960]

La Nación [Buenos Aires, 1965-1970]

La Prensa [Buenos Aires, 1965-1967]

Acción [Montevideo, 1960-1962]

El Plata [Montevideo, 1960]

Davar [Tel Aviv, 1961-1962]

Herut [Tel Aviv, 1960-1965]

Al Ha-Mishmar [Tel Aviv, 1965]

Kol Ha'am [Tel Aviv, 1962]

El Debate [Montevideo, 1962]

Lamerchav [Tel Aviv, 1965]

Hatzofé [Tel Aviv, 1962-1965]

Jewish Telegraphic Agency [Nueva York, 1962]

Ma'ariv [Tel Aviv, 1960-1965]

El Popular [Montevideo, 1960]

New Jersey Jewish News [New Jersey, 1962]

Rhode Island Herald [Rhode Island, 1962]

Clarín [Buenos Aires, 1967]

La Prensa [Buenos Aires, 1967]

El Mundo [Buenos Aires, 1967]

La Razón [Buenos Aires, 1967]

Centinela, órgano de la FEDAN [Montevideo, 1961]

\section{Bibliografía citada}

Adín, Yehuda, «Nacionalismo y Neonazismo en Argentina,» [en hebreo] Betfutzot Hagola 7, no. 33 (1965).

Alonso, Rosa y Carlos Demasi, Uruguay 1958-1968: crisis y estancamiento. Montevideo: Ediciones de la Banda Oriental, 1986.

Amado ,Fernando, Mandato de sangre. Montevideo: Sudamericana, 2012.

Angrick, Andrej y Peter Klein, The Final Solution in Riga: Exploitation and Annihilation, 1941-1944. Oxford: Berghahn Books, 2009.

Bar Zohar, Michael y Nissim Mishal. Mossad: The Greatest Missions of the Israeli Secret Service. Nueva York: Ecco, 2012.

Begin, Menajem, La rebelión en Tierra Santa. Buenos Aires: Santiago Rueda, 1951.

Ben Dror (Blit), Graciela y Victor, Sionismo socialista radical a orillas del Río de La Plata: el Movimiento Mordechai Anielevich en Uruguay, 1954-1976 [en 
hebreo]. Rehovot: Havatzelet Group, 1986.

Black, Ian y Benny Morris, Israel's Secret Wars: A History of Israel's Intelligence Services. Nueva York: Grove Press, 1991.

Bohoslavsky, Ernesto y Magdalena Broquetas, «Vínculos locales y conexiones transnacionales del anticomunismo en Argentina y Uruguay en las décadas de 1950 y 1960", Nuevo Mundo Mundos Nuevos, Mayo, 2017. Web. Consulta: 1 Oct. 2019. http://journals.openedition.org/nuevomundo/70510; DOI: 10.4000/nuevomundo.70510

Broquetas, Magdalena, «A Propósito de las repercusiones del 'Caso Eichmann'. Antisemitismo y Anticomunismo en Uruguay (1960-1962) », EncuentrosUruguayos 3 (2010): 47-63.

- $\quad$ LLos frentes del anticomunismo, Las derechas en el Uruguay de los tempranos sesenta», Contemporánea. Historia y Problemas Del Siglo XX 3 (2012): 11-29.

- $\quad$ La trama autoritaria: derechas y violencia en Uruguay, 1958-1966. Montevideo: Banda Oriental, 2014.

Bucheli, Gabriel, $O$ se está con la patria o se está contra ella: una historia de la Juventud Uruguaya de Pie. Montevideo: Fin de Siglo, 2019.

Cherem, Isaac, Judíos sin kipa, n/p (2019).

DellaPergola, Sergio, Uzi Rebhun and Rosa Perla Raicher. «The Six-Day War and Israel-Diaspora Relations: An Analysis of Quantitative Indicators», The SixDay War and World Jewry. ed. Eli Lederhendler. Bethesda, MD: University Press of Maryland, 2000.

Dirección de Investigaciones, Departamento de Inteligencia y Enlaces Informe de la Policía de Montevideo, «Memoria anual de Investigaciones y Enlaces Año 1965".

Goebel, Michael, «Von der Hispanidad zum Panarabismus», Geschichte und Gesellschaft 37/4 (2011): 523-558.

Halkin, Hillel, Jabotinsky: A Life. London: Yale University Press, 2014.

Harkavi, Itzjak, «En Uruguay durante la época de la captura de Eichmann». Historia viva: memorias del Uruguay y de Israel, (Jerusalén: Universidad Hebrea, 1989), 130-131;

Hendel, Samuel, «Actividades de un joven sionista revisionista montevideano», en Historia viva, pp. 90-92.

https://www.elobservador.com.uy/nota/en-1987-un-nazi-asesino-a-dos-personas-yse-entrego-2016310500.

Jung, María Eugenia, «La Universidad de la Repúbica como enemigo interno: la reacción de las derechas uruguayas, 1958-1973», Anuario IEHS 32/2 (2017): 149-170.

Kaplan, Eran, The Jewish Radical Right: Revisionist Zionism and Its Ideological Legacy. Madison: University of Wisconsin Press, 2005.

Kilstein, Andrés, «Vínculo entre sectores del peronismo de derecha y la Liga Árabe en la Argentina entre 1962-1964", ponencia presentada en el $2^{\circ}$ Congreso de Estudios sobre el Peronismo (1943-1976), UNTreF, Nov. 2010; 
Künzle, Anton and Gad Shimron. The Execution of the Hangman of Riga: The Only Execution of a Nazi War Criminal by the Mossad. Hertfordshire: Mitchell Vallentine \& Co, 2004.

Lambroza, Shlomo, «Jewish Responses to Pogroms in Late Imperial Russia». Living with Antisemitism: Modern Jewish Responses. Ed. Jehuda Reinharz. Hanover and London: Brandeis University Press, 1987.

Markarian, Vania, Uruguay, 1968: Student Activism from Global Counterculture to Molotov Cocktails. Oakland, California: University of California Press, 2017.

Nahum, Benjamín et al. El fin del Uruguay liberal, 1959-1973. Montevideo: EBO, 2007.

Padrón, Juan Manuel. Ni yanquis, ni marxistas! Nacionalistas. La Plata: UNLP, 2017.

Pi Hugarte, Renzo, «Asimilación cultural de los siriolibaneses y sus descendientes en Uruguay», Anuario de Antropología Social y Cultural en Uruguay (2005): 5358 .

Pilosof, Nelson, American Jewish Yearbook. Nueva York: American Jewish Committee, 1964.

Porat, Dina, The Fall of the Sparrow: The Life and Times of Abba Kovner. California: Stanford University Press, 2009.

Porzecanski, Rafael, El Uruguay judío: demografía e identidad. Montevideo: Trilce, 2006.

Raviv, Dan and Yossi Melman, Spies Against Armageddon [en hebreo]. Tel Aviv: Yedioth Aharonot, 2012.

Rein, Raanan, Argentina, Israel y los judíos: encuentros y desencuentros, mitos y realidades. Buenos Aires: Lumiere, 2001.

- «Autodefensa judía en la Argentina de los años '6o. Desafiando el mito de judío como víctima pasaiva», Todo es Historia 575 (2015): 62-79.

Schmelz , U.O. and Sergio DellaPergola, «The Demography of Latin American Jewry», American Jewish Yearbook 85 (1985): 51-102

Senkman, Leonardo, El antisemitismo en la Argentina. Buenos Aires: CEAL, 1986.

Shindler, Colin, The Triumph of Military Zionism: Nationalism and the Origins of the Israeli Right. London: IB Tauris, 2009.

Shorer-Kaplan, Maya, «Ethnic Migration in Comparative Perspective: A Case Study of Jewish Migration from Uruguay to Israel and Other Countries, 1948-2010», Hagira - Israel Journal of Migration 6 (2016): 25-56.

Talty, Stephan, The Good Assassin: How a Mossad Agent and a Band of Survivors Hunted Down the Butcher of Latvia. (Nueva York: Houghton Mifflin Harcourt, 2020).

Triki, Hussein, He aquí Palestina... El sionismo al desnudo. Madrid: Afrodisio Aguado 1977. 